\title{
Attitudinal Epithets in a Children Science Book: A Functional Grammar Analysis
}

\author{
Sri Wahyuni ${ }^{1}$, Eva Tuckyta Sari Sujatna ${ }^{1}$ \& Elvi Citraresmana ${ }^{1}$ \\ ${ }^{1}$ Universitas Padjadjaran, Indonesia \\ Correspondence: Sri Wahyuni, Universitas Padjadjaran, Indonesia. Tel: 62-812-219-6270 or \\ 62-821-1733-3961. E-mail: sri_wahjuni@yahoo.com
}

Received: April 19, 2013 Accepted: May 15, 2013 Online Published: July 17, 2013

doi:10.5539/ijel.v3n4p71 URL: http://dx.doi.org/10.5539/ijel.v3n4p71

\begin{abstract}
The paper titled Attitudinal Epithets in a Children Science Book: a Functional Grammar Analysis analyzes Attitudinal Epithets occurrences in a children's book that intends to explain some scientific phenomena on 'bugs'. Since Attitudinal Epithets are used by speakers or writers in making personal or subjective comments over a phenomenon, they do not normally occur in writings with scientific genre. This paper reveals one of the children's science books used as supplementary resources for Science and English lessons in one of the Private Primary Schools in Bandung city, Indonesia. The analysis is conducted by means of descriptive qualitative methods. The findings provide analytical description over the Attitudinal Epithet's lexical variants that occur in the data; the intensification of Attitudinal Epithets; the scientific, cultural, or other facts in the text preceding or following the Attitudinal Epithets, or outside the text (contextually) to which the speaker directs his personal comment; and the semantic interpretation (including the polarity - negative or positive) towards the Attitudinal Epithets.
\end{abstract}

Keywords: functional grammar, children science book, attitudinal epithet

\section{Literature Review}

\subsection{Functional Grammar}

This paper describes attitudinal epithets in scientific genre, which are analyzed through Functional Grammar (FG) approaches developed by M.A.K Halliday. Halliday's approach to grammar is a semantically driven, which, while not denying that certain principles of syntax do apply, seeks to consider and identify the role of various linguistic items in any text in terms of their function in building meaning (Halliday, 1989, p. xi; Halliday \& Matthiessen, 2004, p. 3). Clauses, phrases, and groups may be viewed in the light of three different metafunctions, the Ideational, Textual, or Interpersonal Metafunction. The Textual metafunction interprets meaning based on whether a linguistic unit is the point of departure, the take-off ground of what the speaker is going to say, or not. While the Interpersonal metafunction tends to seek a language function in enacting a social relationship, whether to inform, offer, request, decline, accept, and the like. The ideational metafunction interprets meaning experientially, from the viewpoint of people's experience of their world. This view of a language brings this paper to the analysis of one of the Experiential Functions of the pre-modifiers in Nominal Groups, the Attitudinal Epithet.

Interpreting meaning of an epithet through anaphoric reference was analyzed by Beller (in http://www.researchgate.net/publication/43648019). By anaphora, paraphrasing attitudinal epithets appropriately depends on the semantic elements or facts in the preceding text(s). In addition to anaphoric reference, this paper, Attitudinal Epithets in Children Science Book, provides other references (the following text or cataphora, and the context surrounding the attitudinal epithets) to interpret the speaker's comments through his choice of attitudinal epithets.

Another linguist investigating attitudinal epithets is J. L. Lemke (http://academic.brooklyn.cuny.edu/). He investigated Attitudinal Epithets as a Head. He classifies the evaluation of Attitudinal Epithets into those indicating the speaker's desirability, warrantability, normativity, usualness, importance, comprehensibility, and humor. This paper provides different classifications. It classifies the Attitudinal Epithets into their lexical variants, intensification strategies, polarity (positive or negative), and aspects to comment on. 


\subsection{Children Science Book}

... the idea that science is too hard for children (especially girls, who are better suited to narrative) and that the language of science (and thus the science) has to be watered down and made personal, expressive, or imaginative for children to understand it. (Martin, 1985 in Halliday \& Martin, 1993, $p$. 194)

The data is taken from a children's science book titled Ugly Buggs (2007). This and other similar books of science for children have been secondarily used by Science and English teachers at one of the private primary schools in Bandung, Indonesia. Prior to their uses, there had been a long debate among the curriculum members, whether or not the school needs to supplement their Science module and textbook with such books. One of the opposing arguments pointed at the frequent use of Attitudinal Epithets contained in the books. The opposing arguers saw those epithets as personal comments, which reduce the scientific sense of the otherwise sufficiently informative learning resources. The description and analysis provided in this paper have helped the books' supporters win their vote. They succeeded in convincing the opponents that the Attitudinal Epithets had raised younger students' interest in science. The ones contained in this type of books are not rude, but entertaining, imaginative, and expressive. Besides, the writers'/speakers' personal comments are not blindly provided solely for the sake of non-scientific attraction, but they refer to the scientific or other informative facts provided explicitly or implicitly by the text.

The broad social function of scientific genre is investigating nature by generalizing, classifying, describing, explaining, and instructing how to observe phenomena (e.g., in experiments), and by recounting and interpreting what was observed (Martin \& Rose, 2008, p. 141). Here, taxonomical or technical terminologies in science are meant to distinguish one classification to another, so that generalization can be made into applicable theories. Yet, they are created to facilitate science learners to precisely tell one scientific class they are learning in relation with the other classes, having a big picture of the scientific world. As quoted above, young science learners need to be aided with personal, expressive, or imaginative scientific language in their effort to comprehend what they are learning. This paper reveals how the data fulfill the three elements above without losing the logical understanding of the scientific phenomena themselves.

\subsection{The Attitudinal Epithet as an Experiential Function in the Nominal Group}

A Nominal Group consists of a Head with optional modifiers. Modifiers include some which precede the Head, pre-modifying elements, and some which follow it, post-modifying elements or qualifiers. The experiential functional elements of pre-modifiers are realized as a Deictic, a Numerative, an Epithet, or a Classifier. The experiential function of the Head is usually a Thing. Modifiers specify the Head by answering 'what type of ...?'. 'what quality of ...?', 'how many ...?', and so on (Halliday \& Matthiessen, 2004, pp. 328-329). The questions to understand those modifying elements are called Experiential Functions because the understanding of the elements is based on people's experience of the world. The distinction of the relative position of modifying elements is semantically significant, such as observed in:

\begin{tabular}{|c|c|c|c|c|c|c|c|}
\hline $\begin{array}{l}\text { (Nominal } \\
\text { Group) }\end{array}$ & those & two & splendid & old & electric & trains & with pantographs \\
\hline (Experiential & \multirow{2}{*}{ Deictic } & \multirow{2}{*}{ Numerative } & \multicolumn{2}{|c|}{ Epithet } & \multirow{2}{*}{ Classifier } & \multirow{2}{*}{ Thing } & \multirow{2}{*}{ Qualifier } \\
\hline Function) & & & Attitude & Quality & & & \\
\hline (Word Class) & Determiner & Numeral & Adjective & Adjective & Adjective & Noun & Prepositional Phrase \\
\hline
\end{tabular}

Figure 1. The relative position of Modifiers in the Nominal Group

(adapted from Halliday \& Matthiessen, 2004, p. 329)

In the Nominal Group analysis above, trains is the Head which is a Thing, realized by a common noun. A Head is mostly a Thing. The Thing is typically expressed by a common noun, proper noun, or a pronoun. Heads may also be realized in grammatical metaphors, phenomena that would typically appear as adjectives or as verbs, as underlined in the clause Nobody's peeling of potatoes is as careful as mine (Halliday \& Matthiessen, 2004, p. 440).

In the Nominal Group above, those is a Specific Deictic to show the relatively far distance between the speaker and the Head trains or to track the referent previously mentioned in the preceding text. The Deictic element 
indicates whether or not some specific subset of the Thing is intended; and if so, which (Halliday \& Matthiessen, 2004, pp. 312-317). The nature of the Deictic is determined by the system of determination, primarily distinguished between Specific and Non-specific Deictic. Non-specific determiners introduce the discourse referent of the Thing, while Specific Determiners track this referent in the text. Another type of Deictic is Post-Deictic, which adds further to the identification of the subset in question. Post-deictic refers to the Thing's fame or familiarity, status in the text, or similarity/ dissimilarity to some other designated subset.

The word two in the Nominal Group analyzed above is an exact quantity Numerative. The Numerative elements indicate some numerical feature of the particular subset of the Thing, either quantity or order, either exact or inexact (Halliday \& Matthiessen, 2004, pp. 317-318).

The noun electric in the Nominal Group analyzed above is a sub-class of train, to distinguish it from other classes like 'coal' or 'diesel'. This is what is called Classifier. Classifiers indicate a particular subclass of the Thing in question. They are typically adjectives or nouns in terms of word classes (Halliday, 1994, p. 185). Classifiers do not accept degrees of comparison or intensity. They tend to be organized in exclusive and exhaustive sets (Halliday \& Matthiessen, 2004, pp. 319-322).

The adjective old in the Nominal Group analyzed above is an Experiential Epithet, while splendid is an Attitudinal Epithet. An Epithet indicates some quality of a Thing. It may be an Experiential Epithet showing the objective property of the Thing (like old, long, blue, fast) or Attitudinal/ Interpersonal Epithet showing the speaker's subjective attitude towards it (like splendid, silly, fantastic) (Halliday \& Matthiessen, 2004, pp. 318-319). In terms of attitude, this paper sees it in two possible polar, negative or positive. Experiential Epithets are potentially defining although not in a sense of exhaustive classification as Classifiers are. Interpersonal ones are not potentially defining.

The following examples show the principle difference of the two Epithets. Long in the long train is an Experiential Epithet. The Specific Deictic the indicates that the listener can tell which train it is. The epithet defines which train by its length, relative to other trains possibly present in the context or text. In a long train, the Non-specific Deictic $a$ does not specify which particular train is discussed. Long in the latter Nominal Group shows the speaker's personal judgment or comment toward the Thing train. However, the Attitudinal Epithet mighty in the mighty train came thundering down the track is not defining, even after being preceded by the Specific Deictic the, mighty. The word mighty does not identify which particular train nor contrast it with the 'un-mighty' ones.

Superlatives are mostly defining as in The silliest things of all were said by the chairman. Nevertheless, in He said the silliest things, silliest remains non-defining as the clause is usually interpreted into He said some very silly things. Interpersonal Epithets tend to precede the Experiential ones, such as in a miserable few dishes of peanuts, where the Attitudinal Epithet miserable precedes the experiential one few. Based on the literal meaning of the adjective miserable (Hornby, 2005), the attitudinal epithet indicates the speaker's attitude that the small amount $(\mathrm{few})$ is depressing or brings uncomfortable feeling to the speaker.

Attitudinal Epithets also tend to be reinforced by other words or features, all contributing to the same meaning. One way is by means of synonyms, for example in a horrible ugly great lump. The adjectives horrible and ugly synonymously indicate 'very bad, unpleasant, unfriendly, unattractive, unlikable, and terrible' (Hornby, 2005). Another way is by means of intensifiers, such as underlined in an awfully sweet lady came. The adverb awfully intensifies the attitudinal epithet sweet with 'very or extremely' (Hornby, 2005). Others are by swear words, particular intonation contours, voice quality features, and the like. This paper includes exclamations, such as Wow!, Yuck!, Aha!, and Ouch! (Halliday \& Matthiessen, 2004, p. 153) as parallel to swear words as the features marking the use of the Attitudinal Epithet.

Verbs may function as Epithet or Classifier in: present (active) participle (V-ing), and past (passive) participle (V-en) (Halliday \& Matthiessen, 2004, p. 321). As Epithets, these forms usually have the sense of the finite tense to which they are most closely related 'which was/ is/ will be ... ing' and 'which had/ has/ will have been ... -en'. As Classifiers, they typically have the sense of simple present. In a galloping horse, galloping is an Epithet as it indicates a horse which is galloping. In a wrecked car, wrecked is an Epithet as it indicates a car which has been wrecked. In a travelling salesmen, travelling is a Classifier as it indicates a salesman who travels. In spoken language, spoken is a Classifier as it indicates 'language which is spoken'.

There is always a Head in a Nominal Group, but it may be of any class (Halliday, 1979, pp. 36-41) or Experiential Function. The function of Head may combine with that of a Deictic/ Post-Deictic/ Numerative/ Epithet, but never with Classifiers since they are normally 'nominal words' (potential to become a new Thing with different meaning). An example of Epithet as Head is underlined in His face grew very flushed and This is 
the best of the three (Halliday, 1979, pp. 148-149).

Borrowing the terminologies used for system of reference in cohesion, the meaning interpretation of an Attitudinal Epithet may have reference through homophora and endophora (Gerot \& Wignell, 1995, pp. 172-174). By homophora, the Attitudinal Epithet meaning refers to the context of cultural knowledge or common sense. Endophora may be an Anaphora or Cataphora. Anaphoricre reference is retrieved from a part in the preceding text, while Cataphoric reference from a part in the following text.

\section{Research Objectives and Methods}

The objectives of this research are to find the lexical variants of Attitudinal Epithets as the speaker's personal comments on a particular fact in the text; the intensification of Attitudinal Epithets; the scientific, cultural, or other facts in the text preceding or following the Attitudinal Epithets, or outside the text (contextually) to which the speaker directs his personal comment; and the semantic interpretation (including the polarity - negative or positive) towards the Attitudinal Epithets.

This paper makes use of Descriptive Qualitative Analysis method based on empirical data, facts, or phenomena from primary sources (Muhammad, 2011, p. 192). The terms 'speaker' and 'listener', as used by Halliday \& Matthiessen (2004), are used in place of 'writer' and 'reader'. First, clauses with Attitudinal Epithets are sorted out from the data. The Epithets are listed down in alphabetical order. Second, Content Analysis technique is then applied to develop replicable and legitimate inferences by considering the context surrounding the data (Bungin, 2007, p. 155). The text preceding or following the Epithets is provided as the meaning interpretation reference. Third, Distributional Analysis is applied to rely upon determinant components in the language itself. One of its techniques is paraphrasing, changing the realization of some components in the language with other forms or realization (Muhammad, 2011, p. 263). The lexical definition as the ground of the Attitudinal Epithets paraphrases refers primarily to Oxford Advanced Learner's Dictionary (Hornby, 2005) and secondarily to Encarta Dictionary (Microsoft, 2008).

\section{Findings}

The findings show the varieties of Attitudinal Epithets found in the data, what facts the text or context they refer to, and the meaning interpretation of each personal comment (Attitudinal Epithet) referring to the facts in the text or context. The same Epithets with similar reference are left out for the sake of effective presentation of varieties.

\subsection{Amazing}

(1) Films are full of insects - especially scary films. There are giant ants and giant flies. And it's amazing how many space monsters look like insects.

The Attitudinal Epithet amazing functions as Head. It shows the speaker's positive judgment towards the large number of insect-looking space monsters in scary films. That fact is very surprising, astounding, incredible, and admirable for the speaker. The scientific fact concerning the number of the insect-looking space monsters is stated in the text preceding the epithet indicated by the quantity full of. In the preceding text, the kinds of space monsters, the giant ants and giant flies, are also stated. The facts are concluded in the it substitute (how many space monsters look like insects) following the Attitudinal Epithet.

(2) Amazing internal heating system in abdomen heats chemical to temperature of $100^{\circ} \mathrm{C}$ and fires at 500 to 1000 squirts a second!

The Attitudinal Epithet amazing shows the speaker's personal judgment towards the subset of the Head (internal heating system in abdomen). The rising intonation contour (!) gives the Attitudinal Epithet an emphasis. The personal judgment is directed to the scientific fact in the text following the Attitudinal Epithet. The fact is the capability of the system to raise the chemical temperature up to $100^{\circ} \mathrm{C}$ in order to fire at 500 to 1000 squirts a second. Therefore, the speaker positively deems the internal heating system in abdomen to be very surprising, astounding, incredible, and admirable.

(3) Butterflies and many moths have amazing coloured patterns on their wings. These colours are made up of tiny overlapping scales and they help male and female butterflies to find each other before mating.

The Attitudinal Epithet amazing shows the speaker's personal judgment towards the subset of the Head (colored patterns on their wings). The species in question are butterflies and many moths. The speaker's personal comment is directed to the scientific fact in the text following the Attitudinal Epithet. The fact explains the physical features, the wing patterns, in further details and the function of the color combination in mating season. Therefore, the patterns are very surprising, astounding, incredible, and admirable (positive) for the speaker. 


\subsection{Awesome}

(4) Because the ants from each nest eat an awesome 100,000 caterpillars and other ugly pests every day.

The Attitudinal Epithet awesome shows the speaker's personal judgment towards the subset of the Head (caterpillars and other ugly pests). The speaker directs his personal comment to the scientific fact stated in the text following the Attitudinal Epithet. The speaker positively comments that the number and types of pests eaten by the ants are very impressive.

(5) You can't see their wings because in some varieties they beat at an awesome 62,760 strokes a minute. That's why some people call midges "no-see-um".

The Attitudinal Epithet awesome shows the speaker's personal judgment towards the subset of the Head $(62,760$ strokes). The speaker directs his personal comment to the scientific fact stated in the text following the Attitudinal Epithet. The number of strokes the midges can make every minute is very impressive (positive) for the speaker. This fact is elaborated with the nick name given to midges, the "no-see-um", which refers to the humming sound resulted by the quick and frequent strokes of the midges' wing.

\section{$3.3 \mathrm{Awful}$}

(6) Are earthworms awful? "Yes", according to people who don't like slimy wriggling creatures.

The Attitudinal Epithet awful functions as Head. It shows the speaker's interpretation of other people's personal judgment towards earthworms. The fact about such people is provided in the text following the Attitudinal Epithet, emphasized by the mood adjunct yes. The text negatively reveals that the people who would call the earthworms very bad, unpleasant, and terrible are the ones who don't like slimy wriggling creatures. The epithet refers to the physical feature or texture of the earthworms.

(7) They (army ants) spend their time invading places and being awesomely awful to any creature that gets in their way. If you live in South America, it could get rid of cockroaches in your home, but you'd have to get yourself out of the way first.

The Attitudinal Epithet awful is intensified by the adverbial group awesomely. The intensified Attitudinal Epithet functions as Head. It shows the speaker's personal judgment towards the impact of army ants' invasion. The scientific fact about the ants' invasion is stated in the text preceding the epithet. The scientific fact about their favor as well as their terrible impact to humans in South America is provided in the text following the Attitudinal Epithet. The texts reveal the scientific fact that the army ants invades places most of their time and endanger all creatures that they encounter, including cockroaches and humans. Therefore, the speaker negatively deems the army ants to give extremely bad, unpleasant, and terrible impact to any creatures they encounter.

(8) Ants can be pretty awful - they get everywhere from your plants to your pants.

The Attitudinal Epithet awful is intensified by the adverbial group pretty. The intensified Attitudinal Epithet functions as Head. The speaker directs his personal judgment to the scientific fact provided in the text following the Attitudinal Epithet. The text reveals the ants' habits as they swarm round any creatures, including vegetation and human. Therefore, the speaker negatively deems those habits to be giving bad, unpleasant, and terrible impact.

$3.4 \mathrm{Bad}$

(9) The garlic grass snail smells strongly of garlic. But it must give snail-eating birds horribly bad breath.

The Attitudinal Epithet bad is intensified by the adverbial group horribly. The intensified epithet shows the speaker's personal judgment towards the Head (breath). The scientific fact about what causes the horribly bad breath is stated in the text preceding the Attitudinal Epithet. Whereas the unpleasant smell of garlic in general refers to contextual common sense. Therefore, the speaker negatively deems the breath to be extremely unpleasant.

3.5 Big, Strong

(10) And even big strong humans run for their life rather than face it. Nothing can fight against it (an army ant) and live.

The Attitudinal Epithets big and strong are synonymous. They intensify each other in modifying the Head (humans). Together they show the superior (positive) physical feature of humans relative to ants - powerful, large, and hard to defeat and to break. The speaker directs his personal judgment to the scientific fact revealed in the text following the attitudinal epithet. The text states that despite humans' superior physical characteristics, they would save themselves from the army ants as the ants' attack is undefeatable by humans. 


\subsection{Boring}

(11) Woodlice themselves have a horribly boring diet, though. They prefer bits of rotting plants and moulds. It's not everyone's cup of tea.

The Attitudinal Epithet boring is intensified by the adverbial group horribly. The intensified epithet shows the speaker's personal judgment towards the Head (diet). The speaker gives his personal comment based on the scientific fact and the expression revealed in the texts following the Attitudinal Epithet. The scientific fact about what causes such judgment is the kinds of food - rotting plants and moulds. The fact is emphasized with the idiomatic expression it's not everyone's cup of tea, which shows the distaste towards such food. Therefore, the speaker negatively deems the woodlice' food to be dull and not interesting.

\subsection{Brilliant}

(12) Learn basic backstroke with our brilliant backswimming water boatman beetle.

The Attitudinal Epithet brilliant shows the speaker's personal judgment towards the subset of the Head (water boatman beetle). The scientific fact that explains the meaning of the classifier backswimming is in the text preceding the Attitudinal Epithet, through the Head backstroke in the Nominal Group basic backstroke. The fact basic backstroke does not indicate the brilliant competence straightforwardly. Thus the Attitudinal Epithet as the speaker's personal judgment is given based on contextual common sense as well, that backstroke swimming done by beetle shows special skill and impresses humans. Therefore, the speaker positively deems the beetle's capability in swimming on their backs to be very skillful and impressive.

\subsection{Complicated}

(13) These scientists were the first lepidopterists - a horribly complicated name for people who study butterflies and moths.

The Attitudinal Epithet complicated is intensified by the adverbial group horribly. It shows the speaker's personal judgment towards the Head (name). That Head is specified in the text preceding the Attitudinal Epithet as a terminology/ proper noun lepidopterists. The speaker emphasizes the complexity by providing the definition of lepidopterists - people who study butterflies and moths, in the text following the Attitudinal Epithet. The definition implies the discrepancy between the 'simple' definition and the 'difficult or complicated to pronounce' terminology. Therefore, the speaker negatively deems the terminology to be very difficult to understand and very complex.

\subsection{Confusing}

(14) It all sounds horribly confusing. And horribly boring. But it shouldn't be. You see, science isn't about all-knowing experts in white coats and laboratories and high-tech gadgetry. Science is about us. How we live and what happens to us every day.

The Attitudinal Epithet confusing is intensified by the adverbial group horribly. There is another Attitudinal Epithet that occurs. It is boring and intensified by the adverbial group horribly. Both intensified epithets function as a Head. Both show negative personal judgment listeners (you) may have towards science. The speaker contradicts such judgment in the text following both Attitudinal Epithets. The speaker explains that science may be not clear thus very difficult to understand as well as dull and not interesting if listeners merely view science in terms of its experts, laboratories, and high-tech equipment. The speaker conveys how listeners should view science - the source of knowledge on human life and experience.

\subsection{Cruel}

(15) But what was the cruel connection between rats, fleas, and humans? Microbes multiply in the flea's gut until it can't feed. The hungry flea bites a human and injects millions of germs.

The Attitudinal Epithet cruel shows the speaker's personal judgment towards the subset of Head (connection between rats, fleas, and humans). The speaker refers to the scientific fact in the text following the Attitudinal Epithet as the basis of his personal judgment. In that text, the connection is elaborated into a feeding habit or chain. The feeding chain starts from microbe multiplication in the flea's stomach that afflicts the flea's inability to feed up to the number of germs injected to human's body during the flea's feeding time. Therefore, the speaker negatively deems the chain or connection to cause pain or suffering.

(16) So they use some cruel and cunning tricks to get one up on their ugly bug enemies. ... The praying mantis really does look as though it's praying. It holds its forelegs together as it waits for a tasty snack to pass by. ... will catch and skewer its bug lunch ... then bite off its ugly little head. 
The Attitudinal Epithets cruel and cunning show the speaker's personal judgment towards the subset of the Head (tricks to get one up on their ugly bug enemies). The scientific fact elaborating the tricks or strategies is revealed in the text following the Attitudinal Epithet. In that text, the ingenuity refers to the praying mantis' pose as if it were praying, whereas it is actually waiting for its prey to pass. The pain and suffering describe the speaker's judgment when explaining how the mantis skewers and bites off the head of its prey. Therefore, the speaker negatively deems the tricks to cause pain and suffering yet positively to be ingenious and clever.

(17) You'd do well to avoid this little cruel cat (puss moth caterpillar), as it can spit out its half digested dinner mixed with awful acid.

The Attitudinal Epithet cruel shows the speaker's personal judgment towards the Head (cat). The speaker directs his personal comment to the scientific fact revealed in the text preceding and following the Attitudinal Epithet. In the following text, the puss moth caterpillar is described to have an ability to spit out its half digested dinner mixed with awful acid. This fact shows a capability that listeners would avoid, as stated in the preceding text. This capability is seen to cause pain and suffering for the speaker. Another Attitudinal Epithet awful indicates the very bad, unpleasant and terrible nature of the acid. The latter epithet intensifies the sense of 'cruelty'.

\subsection{Cute}

(18) Cute little fairy flies are actually tiny wasps only $0.21 \mathrm{~mm}$ long. The good news is they don't stink humans.

The Attitudinal Epithet cute shows the speaker's personal judgment towards the subset of the Head (little fairy flies). The speaker directs his personal comment to the scientific fact revealed in the text following the Attitudinal Epithet. In that text, the 'cuteness' is related to the flies' size - tiny, and their gentle nature for not stinking humans. Therefore, the speaker positively deems flies to be pretty and attractive.

(19) A sea mouse, on the other hand has a mouse-shaped body that's all furry. Aahh, sounds quite_cute, doesn't it? Except that this worm can grow up to $18 \mathrm{~cm}$ (7 inches) long, and $7 \mathrm{~cm}$ (3 inches) wide. Sound more like a sea rat!

The Attitudinal Epithet quite cute functions as the Head. The adverbial group quite intensifies the Attitudinal Epithet cute. The epithet shows that the speaker positively deems the sea mouse to be to a great degree or completely pretty and attractive. The speaker directs his personal comment to the scientific fact revealed in the text preceding and following the Attitudinal Epithet. The preceding text shows the elaboration of why the texture of a sea mouse is deemed quite cute. That cuteness is further intensified by the tag doesn't it. The following text provides the opposite comparison between its body shape and its ability to grow very long and wide. The Conjunctive Adjunct except introduces this opposite judgment in the following text. While the furry mouse shape is considered quite cute, the massive growth is considered like a sea rat. In the contextual common sense, a rat is bigger than, not as cute as a mouse. The distinction is further intensified by the rising intonation contour (!).

\subsection{Devilish}

(20) Watch carefully as it blows bubbles from the end of its body to cover itself up again. ... OK, so maybe the froghopper doesn't want to make friends, but you've got to admit it's got a devilish disguise.

The Attitudinal Epithet devilish shows the speaker's personal judgment towards the Head (disguise). The scientific fact elaborating the devilish look is revealed in the text preceding the Attitudinal Epithet. The froghopper produces bubbles to hide its body from other creatures it encounters. The speaker negatively deems the look or appearance to be evil looking. The relationship between the disguise and cruel or evil characteristic is affirmed narratively with the possible reason for such disguise - its reluctance to make friends.

\subsection{Disgusting}

(21) Chances are that these creepy crawlies - included centipedes, millipedes and woodlice. ... Centipedes like to eat millipedes - when they get the chance. And that's just the start of their disgusting differences!

The Attitudinal Epithet disgusting shows the speaker's personal judgment towards the Head (differences). The speaker directs his personal comment to the scientific fact revealed in the text preceding the Attitudinal Epithet. The difference in terms of what they (centipedes, millipedes, and woodlice) eat, besides other differences, is negatively deemed revolting or nauseating by the speaker. The start of the differences indicates that one type of those bugs, the centipedes, eats another type, the millipedes. This comment is further intensified by the rising intonation (!).

(22) Yuk! Tastes disgusting! Grey meerkats always feed on millipedes.

The Attitudinal Epithet disgusting functions as the Head. It shows the speaker's personal judgment towards some 
scientific fact. The speaker directs his personal comment to the scientific fact revealed in the following passage about what meerkats eat. Based on the fact, the speaker negatively deems that the the meerkats' taste is revolting or nauseating. This judgmet is intensified by the use of the uprising intonation contour (!) and the exclamative Yuk.

\subsection{Dramatic}

(23) Then he made a dramatic discovery. In the rat's blood he found the germs known to cause the plague.

The Attitudinal Epithet dramatic shows the speaker's personal judgment towards the Head (discovery). The speaker directs his personal comment to the scientific fact revealed in the text following the Attitudinal Epithet. The text reveals the finding impact of plague that causes germs in the rat's blood. The speaker positively deems the discovery to be great, surprising, and attracting people's attention. The discovery is deemed to be extraordinary for people in general.

\subsection{Dull}

(24) You may think that earthworms are deadly dull and boring. But delve a little deeper into the humdrum lives and you will discover some slimy surprises.

The Attitudinal Epithets deadly dull and boring function as the Head. The Attitudinal Epithet dull is synonymous to boring. They intensify each other. Both epithets are intensified further by an adverbial group deadly. The whole epithets show that the speaker thinks earthworms are completely dreary and not interesting for the listeners, represented by the pronoun you as the subject. The text following the epithet starts with the conjunctive adjunct but to show the contradiction of the previous judgment interpretation (completely dreary and not interesting) and the judgment in the following text. The text following the epithets gives a clue that the next elaboration about earthworms is the opposite of 'completely dreary and boring' life. The epithet humdrum, which also negatively means boring, dull, and always the same, is contrasted with the noun surprises, which means 'startling, amazing, stunning, and astonishing events'.

3.16 Evil

(25) Evil Ero then sucks its victim dry and scurries away, leaving an empty spider husk sitting in its web.

The Attitudinal Epithet evil shows the speaker's personal judgment towards the Head (proper noun) Ero. The speaker directs his personal comment to the scientific fact revealed in the text following the Attitudinal Epithet. The text reveals the fact about how an Ero feeds on all its victim's soft tissue or internal organs. The speaker negatively deems Ero's appetite to be morally bad and cruel for enjoying harming others.

\subsection{Fearsome}

(26) Mayflies ... they mate, lay their eggs, and die. Ugly bugs and fearsome fish go crazy banqueting on the bodies.

The Attitudinal Epithet fearsome shows the speaker's personal judgment towards the Head (fish). The scientific fact elaborating the fearsome characteristic is revealed in the text following the Attitudinal Epithet. The text reveals the fish' feeding habit - crazily or greedily consume dead mayflies. The speaker negatively deems the fish' appetite to be very frightening.

(27) Some of these monsters have fearsome fangs. One type of centipede in the Solomon island has a particularly painful bite.

The Attitudinal Epithet fearsome shows the speaker's personal judgment towards the Head (fangs). The speaker directs his personal comment to the scientific fact revealed in the text following the Attitudinal Epithet. The fact states the painful bite, the effect, caused by a type of centipede in the Solomon island. In relations with the Head fangs, this paper concludes that the centipede bites with its fang. Therefore the speaker negatively deems the fangs to be very frightening. The very frightening characteristic is emphasized by the speaker through the comparison between monsters and the types of centipede in general.

\subsection{Fiendish}

(28) The plague reached India and killed six million people in ten years. ... Day and night he (Dr Paul-Louis Simond of the Institut Pasteur) wrestled with the same fiendish puzzle.

The Attitudinal Epithet fiendish shows the speaker's personal judgment towards the Head (puzzle). The speaker directs his personal comment to the scientific fact revealed in the text preceding the Attitudinal Epithet and the Head itself. The puzzle resembles the intricate problems caused by the plague that killed six million people in ten years. That resemblance is indicated by the Post-deictic same modifying the subset of the Head fiendish puzzle. 
For the speaker, the problem is negatively deemed to be extremely clever and complicated but cruel. The clever and complicated but cruel characteristic is emphasized by the choice of process wrestled, which literally means 'fought to force someone to fall onto the ground' and figuratively means 'dealt with or struggling with something that is difficult'.

3.19 Funny

(29) Funny thing is that the meerkats always screw their faces up in disgust when they're eating (giant millepedes).

The Attitudinal Epithet funny shows the speaker's personal judgment towards the Head (thing). The speaker directs his personal comment to the scientific fact revealed in the text following the Attitudinal Epithet. The text reveals the fact that the meerkats up-screw their face in disgust when they are eating giant millipedes. Therefore the speaker positively deems the facial reaction or look as to making people laugh or amusing people who see it.

\subsection{Gruesome}

(30) Ugly Dug wraps them up in a slimy parcel and just sucks bits off them. ... and it's almost see-through, so you can see what it ate for dinner. ... Sometimes they have weird tube-like structures that shoot out from their heads ... The weird worms in this gruesome group all have rounded bodies that divide into segments.

The Attitudinal Epithet gruesome shows the speaker's personal judgment towards the Head (group) that refers to the worms called Ugly Dugs. The speaker directs his personal comment to the scientific fact revealed in the text preceding the Attitudinal Epithet. That text reveals Ugly Dugs' strange looking parts of body; the see-through body enables people to see their digesting process; their head can shoot out weird structures. The other epithet with similar sense, weird, is mentioned twice to intensify the gruesome quality. Therefore the speaker negatively deems both facts to be very unpleasant and filling with horror because it is connected with death or injury.

(31) But size doesn't save either the giant centipedes or the giant millipedes from a horrible gruesome_death. In the African savannah giant hornbills are often seen plodding along looking at the ground. Suddenly they will nab a passing centipede in their long beak and the centipede has no chance to bite the bird back.

The Attitudinal Epithet is realized by two synonymous adjectives horrible and gruesome, which intensify each other. The Attitudinal Epithets show the speaker's personal judgment towards the Head (death) that refers to that of the centipede. The speaker directs his personal comment to the scientific fact revealed in the text preceding and following the Attitudinal Epithet. The preceding text emphasizes the speaker's personal judgment by contrasting the sense of 'large size' in the word giant with the miserable way the centipedes die. The way they die is elaborated in the text following the epithets. The centipedes' large size is defeated by larger animals, the hornbills. The way they die is described through the how powerfully hornbills catch a passing centipede unguarded with their beak, making the centipede powerless to fight back. Therefore the speaker negatively deems the way and cause of the death to be very unpleasant and filling with horror.

\subsection{Horrible}

(32) So they do have some horrible habits. After the earth has passed through their bodies it ends up in ugly earthworm-shaped piles all over your beautiful front lawn. Earthworms love to guzzle lettuce and their burrowing can damage plant seedlings.

The Attitudinal Epithet horrible shows the speaker's personal judgment towards the Head (habits) that refers to that of the earthworms'. The speaker directs his personal comment to the scientific fact revealed in the text following the Attitudinal Epithet. The text reveals damaging feeding habits to people's beautiful lawn caused by earthworms. Earthworms burrow, digest, then excrete the earth in piles resembling their shape and size, and swallow lettuce in people's lawn. Therefore the speaker negatively deems those habits to be very bad, unpleasant, dislikable, shocking, terrible, nasty, and obnoxious.

(33) And at all times, horrible humans chuck in harmful rubbish and poisonous pollution.

The Attitudinal Epithet horrible shows the speaker's personal judgment towards the Head (humans) that refers to their habit in particular. The speaker directs his personal comment to the scientific fact revealed in the text following the Attitudinal Epithet. The text reveals humans' bad habit as they throw away rubbish and carry out activities that cause pollution, which in turn intoxicate or harm life. Therefore the speaker negatively deems that habit to be very bad, unpleasant, dislikable, shocking, terrible, nasty, and obnoxious.

(34) For us humans the most horrible thing about insects is the way they bite us. And suck blood and sometimes give us horrible disease too. 
The Specific Deictic the does not make the epithet most horrible experiential or defining. The word most intensifies the epithet horrible and affirms to listeners that most horrible thing is an Attitudinal Epithet which means 'some very horrible things'. The Attitudinal Epithet most horrible shows the speaker's personal judgment towards the subset of the Head (thing about insects). The speaker directs his personal comment to the scientific fact revealed in the text following the Attitudinal Epithet. The text reveals the bad habit and the effect insects have on humans - biting, sucking blood, and sometimes giving horrible disease. Therefore the speaker negatively deems those deeds to be very bad, unpleasant, dislikable, shocking, terrible, nasty, and obnoxious.

\subsection{Important}

(35) Gilbert White wrote in 1770, "Earthworms though in appearance a small and despicable link in the Chain of Nature, yet if lost would make a lamentable chasm." Charles Darwin called earthworms, "Earthworms have played a most important part in the history of the world."

The word most intensifies the epithet important but does not make it experiential or defining. The use of the non-specific Deictic $a$ instead of the affirms to listeners that most important part is an Attitudinal Epithet which means one of 'some very important parts'. The Attitudinal Epithet most important shows Darwin's personal judgment towards the Head (part). Darwin directs his personal comment to the scientific fact revealed in the text preceding the Attitudinal Epithet. The text reveals Gilbert White's similar opinion about 'the greatly valuable and influential or powerful role of earthworms in the chain of nature' by elaborating it with the disadvantage that is going to afflict mankind if one component (the earthworms) in the link or chain is extinct. Therefore Darwin positively deems earthworms' role to be greatly valuable and influential on people or things.

\subsection{Incredible}

(36) And isn't it amazing that there are thousands of different kinds of butterfly throughout the world in an incredible variety of shapes and forms.

The Attitudinal Epithet incredible shows the speaker's personal judgment towards the subset of the Head (variety of shapes and forms). The speaker directs his personal comment to the scientific fact revealed in the text preceding the Attitudinal Epithet. The text reveals the large number of kinds of butterfly throughout the world and intensifies the incredibility using another Attitudinal Epithet amazing which similarly means very surprising, astounding, incredible, and admirable. Therefore the speaker positively deems the variety to be unbelievable and extremely large in number.

\subsection{Interesting}

(37) Woodlice have extremely interesting relatives. Crabs, shrimps, prawns, lobsters and woodlice are all part of the crustacean family.

The Attitudinal Epithet extremely interesting shows the speaker's personal judgment towards the Head (relatives). The adverbial group extremely intensifies the epithet. The speaker deems Woodlice's relatives, crabs, shrimps, prawns, and lobsters, to be very attractive or unusual. Because no scientific elaboration is provided in the preceding or following text, this paper interprets the speaker's personal judgment based on contextual common sense. Crabs, shrimps, prawns, and lobsters are much bigger than woodlice. That size difference is probably why the speaker positively deems the family relationship to be very attractive or unusual.

(38) You could be in for a horribly interesting encounter! You can tell where there are slugs around by the horrible silvery slime trails they leave.

The Attitudinal Epithet horribly interesting shows the speaker's personal judgment towards the Head (encounter). The adverbial group horribly intensifies the epithet and refers to another Attitudinal Epithet horrible in the following text. The text states that the presence of slugs in a particular area is marked by silvery slime trails that look horrible. As the lexical meaning of horrible is very bad, unpleasant, dislikable, shocking, terrible, nasty, and obnoxious, the Attitudinal Epithet horribly interesting then explains that the speaker negatively deems the encounter to be very attractive and unusual in an unpleasant way. The rising intonation at the end of the clause also intensifies the epithet.

(39) Some woodlice live in horribly interesting places. One variety lives inside yellow ants' nests and eats their droppings. Another type of woodlouse lives by the seaside under piles of slippery rotting seaweed.

The Attitudinal Epithet horribly interesting shows the speaker's personal judgment towards the Head (places). The adverbial group horribly intensifies the epithet. The speaker's personal judgment is directed to the scientific fact revealed in the text following the epithet. The places or environment mentioned are inside yellow ants' nests 
and by the seaside under piles of slippery rotting seaweed. As the lexical meaning of horrible is very bad, unpleasant, dislikable, shocking, terrible, nasty, and obnoxious, the Attitudinal Epithet horribly interesting then explains that the speaker negatively deems the places to be very attractive and unusual in an unpleasant way.

\subsection{Irritating}

(40) Irritating insects. ... Earwigs get their name from the barmy belief that they crawl into your ears when you're asleep.

The Attitudinal Epithet irritating shows the speaker's personal judgment towards the Head (insects). The insects in question are Earwigs. The annoying habit the Earwigs do is in the text following the epithet. The text does not reveal any scientific fact, but instead it reveals an irrational belief that earwigs continuously annoy some people who are sleeping 'by crawling into their ears'. The speaker negatively deems the 'what the Earwigs do in the belief' to be annoying for what they do continuously.

(41) Most irritating fly habits: flying backwards, sideways, and forwards round your head. OK - so you know they are incredible flyers already.

The superlative adverb most intensifies the epithet irritating but does not make it experiential or defining. The epithet means 'some very irritating flying habits'. The speaker directs his personal comment to the scientific fact revealed in the text preceding the Attitudinal Epithet. The text states that flies annoy people by flying in various directions round people's or listeners' head. Therefore the speaker negatively deems the fly habits to be annoying for the way they fly continuously.

3.26 High

(42) Here, heated chemicals, stinking like rotten eggs, boiled up from below at terrifically high temperatures.

The adverbial group terrifically intensifies the Experiential Epithet high. The non-defining intensifier terrifically reduces the defining power of high. Since the lexical meaning of terrifically is extremely in a positive way, excellently, or wonderfully, the temperature height is seen positive by the speaker. The speaker directs his personal comment to the scientific fact revealed in the text preceding the Attitudinal Epithet. The fact reveals the depth the heated chemicals boil up from. The word boiled is seen as comparable to 'reaching very high temperature'. Therefore the speaker personally deems the temperatures to be extremely or wonderfully high.

\subsection{Loathsome}

(43) See if you can match each ugly bug to its loathsome lifestyle? Grabs a passing bug in its claws and sucks out the juices. Eats anything that moves. Eats tiny plants. Walks around on the surface looking for bugs that have fallen in. Eats other pond bugs.

The Attitudinal Epithet loathsome shows the speaker's personal judgment towards the Head (lifestyle). The speaker directs his personal comment to the scientific fact revealed in the text following the Attitudinal Epithet. The text reveals a feeding habit. An ugly bug eats anything that moves, eats small plants, and kills its prey with its claws and sucks out most of the prey's body organ. Therefore, the speaker negatively deems the ugly bug's lifestyle as extremely unpleasant, disgusting, and repulsive.

(44) Lurking at the bottom of your local pond or canal is a creature that makes the others seem quite likeable. There's no way of disguising it. These creatures (leeches) are loathsome!

The Attitudinal Epithet loathsome functions as the Head. It shows the speaker's personal judgment towards leeches. The rising intonation contour (!) intensifies the epithet. The speaker directs his personal comment to the scientific fact revealed in the text preceding the Attitudinal Epithet. The process seem and qualifier of disguising it tell that it is the 'look' which is discussed here. The Nominal Group a creature that makes the others seem quite likeable implies that the other creatures are also described ugly looking, but still better than leeches. Therefore, the speaker negatively deems the leeches' look as extremely unpleasant, disgusting, and repulsive.

\subsection{Lovely}

(45) Lovely ladybirds can gobble up 100 green fly a day.

The Attitudinal Epithet lovely shows the speaker's personal judgment towards the Head (ladybirds). There is no scientific fact that supports the interpretation of the speaker's judgment in the text following and preceding the Attitudinal Epithet. The speaker positively deems ladybirds' look as very attractive, beautiful, wonderful, and pleasant to see based on contextual common sense of how ladybirds commonly look. 


\subsection{Messy}

(46) In Zaire people make beer from cassava roots. The messy mixture produces carbon dioxide gas that lures the flies to their doom.

The Attitudinal Epithet messy shows the speaker's personal judgment towards the Head (mixture). There is no scientific fact that supports the interpretation of the speaker's judgment in the text following and preceding the Attitudinal Epithet. The speaker negatively deems the beer, the mixture of cassava roots, as untidy based on contextual common sense of how cassava root mixture commonly looks.

\subsection{Mysterious}

(47) Science can be horribly mysterious. ... For example, what do scientists do all day? Ask a scientist and you'll just get a load of scientific jargons.

The Attitudinal Epithet horribly mysterious functions as the Head, with the adverbial group horribly intensifying the epithet mysterious. It shows the speaker's personal judgment towards science. The speaker directs his personal comment to the scientific fact revealed in the text following the Attitudinal Epithet. The speaker personally deems science as difficult to understand or explain, strange and interesting because people do not know much about it. This personal judgment refers to one example of science mystery or complexity, which is the large number of scientific jargons - words or expressions that are used by a particular profession or group of people. The mysterious characteristic negatively implies that according to the speaker, many people do not understand much about scientific jargons.

\subsection{Nasty}

(48) Leeches are the nasty bloodsuckers. When a leech sucks blood it can swell up to three times its original size!

The Attitudinal Epithet nasty shows the speaker's personal judgment towards the Head (bloodsuckers). The speaker negatively deems leeches, that he calls bloodsuckers, as very bad, unpleasant, unkind, mean, threatening, and violent. This personal judgment is directed to the Head itself and the elaboration of the Head, the scientific fact, is in the following text. The head bloodsuckers tells the listener that leeches suck blood. That unpleasant, unkind, mean, threatening, and violent way to feed is added with how much blood they suck that makes their body swell up to three times their original size. So the direct reference is the feeding habit or greed; the size is only the indirect reference.

(49) It will produce nasty tasting liquid. This will definitely put you off eating it.

The Attitudinal Epithet nasty tasting is an active participle verbal group which, in relation with the Head, means liquid that tastes nasty. This personal judgment is directed to the comment in the text following the Attitudinal Epithet. The comment says that the liquid's nasty taste that it produces will stop the listener from a desire to eat it. Therefore, the speaker negatively deems the liquid as very unpleasant and in bad taste.

(50) Nastiest fly habit: some types of fly like nothing better than to lick the top of a big smelly cowpat.

The Attitudinal Epithet nastiest is a superlative but this form does not make the epithet defining or experiential since, in relation with the Head, the Nominal Group means 'some very nasty fly habits'. This personal judgment is directed to the scientific fact in the text following the Attitudinal Epithet. The text reveals the most common unpleasant habit of flies, which is licking smelly substance like cowpat. Therefore, the speaker negatively deems the fly habit to be unpleasant or in very bad taste.

(51) But sometimes more than one queen hatches out, and things can turn rather nasty. The first queen to appear kills off any rivals.

The Attitudinal Epithet nasty functions as Head. It shows the speaker's personal judgment towards the scientific fact that comes up in the text preceding and following the Attitudinal Epithet. The preceding text shows some occasions when there is more than one queen hatching out. The following text reveals the fact that the first queen hatching out kills her rivals. Therefore, the speaker negatively deems the effect of hatching more than one queen to be very bad, unpleasant, unkind, mean, threatening, and violent.

\subsection{Odd}

(52) And woodlice do liven up their diet the odd interesting dish ... like other woodlice for instance. Or their own droppings and their skin after they've shed it.

The Attitudinal Epithets imply that the Head dish is interesting in odd sense. The scientific fact that the epithet is directed to is revealed in the text following the Attitudinal Epithet. The text reveals the fact that woodlice feed on 
other woodlice, their own droppings, and their own shedding skin. Therefore, the speaker negatively deems woodlice dish or taste to be unusual or attractive in a strange or weird sense.

\subsection{Poor}

(53) But sinister centipedes gobble up the poor little millipedes and not the other way round.

The two adjectives poor and little intensify each other as the Attitudinal Epithets that show the speaker's personal judgment towards the Head (millipedes). The speaker's personal judgment is directed to the scientific fact provided in the text preceding and following the Attitudinal Epithet. The texts simultaneously reveal the reason why the speaker negatively deems the millipedes to be pitiful and unfortunate for having smaller size compared with the centipedes which are deemed to be seeming evil and alarming danger. The millipedes become (the effect) pitiful and unfortunate for being preyed and eaten by the centipedes.

\subsection{Precious}

(54) There, some of the precious pollen brushes on to the flower, fertilizes it and so helps it form a seed.

The Attitudinal Epithet precious shows the speaker's personal judgment towards the Head (pollen). The speaker directs his personal comment to the scientific fact revealed in the text following the Attitudinal Epithet. The speaker positively deems the pollen as valuable, treasured, and not to be wasted since it plays a valuable role in the flower's reproduction cycle.

\subsection{Revolting}

(55) Some (mites) eat cheese rinds and the glue in old books. Others suck blood from animals. They like nothing better than a breakfast of slimy rotten leaves. And some worms have even more revolting tastes.

The Attitudinal Epithet more revolting shows the speaker's personal judgment towards the Head (tastes). The intensifier more indicates that the scientific fact provided is 'less revolting' than that of the Head tastes. The speaker directs his personal comment to the scientific fact revealed in the text preceding the Attitudinal Epithet. The text contains mites' food or taste: cheese rinds, glue in old books, animal blood, and slimy rotten leaves. With the intensifier more, the speaker negatively deems the worms' tastes as extremely unpleasant and disgusting, more than the mites'.

\subsection{Romantic}

(56) When slugs mate ... they fire little arrows called love darts at one another to get in the mood. Very romantic - if you're a slug!

The Attitudinal Epithet very romantic functions as Head. The adverbial group very intensifies the epithet romantic for the speaker to affirm his personal judgment towards the description provided in the text preceding the Attitudinal Epithet. The slug mating process or habit is described in comparison to firing little arrows called love darts at one another to get in the mood. This comparison is positively deemed to be connected with the beauty of love by the speaker. The rising intonation contour (!) at the end of the clause further intensifies the comment.

\subsection{Savage}

(57) Maybe it's because spiders have some seriously savage habits. ... Paralysis prey with poison fangs and sucks out the juices.

The Attitudinal Epithet seriously savage shows the speaker's personal judgment towards the Head (habits). The adverbial group seriously intensifies the epithet savage for the speaker to affirm his personal judgment towards the scientific fact provided in the text following the Attitudinal Epithet. The text reveals spiders' habits to paralyze their prey with poison fangs and suck out its juices. Therefore the speaker negatively deems the habits to be primitive, aggressive, and harmful.

(58) This savage spider then stabs its victims through the web with its long poison fangs.

The Attitudinal Epithet savage shows the speaker's personal judgment towards the Head (spider). The speaker's personal judgment is directed to the scientific fact provided in the text following the Attitudinal Epithet. The text reveals how (the strategy) the spider traps and paralyzes its victims. Therefore, the speaker negatively deems that action to be primitive, aggressive, and harmful.

\subsection{Serious}

(59) Guard-termites are so serious about their work they sometimes explode in a bid to defend the nest!

The Attitudinal Epithet so serious functions as Head. The adverbial group so and the rising intonation contour at 
the end of the clause intensify the epithet serious for the speaker to affirm his personal judgment towards the scientific fact provided in the text following the Attitudinal Epithet. The text reveals guard-termites' perseverance in defending their nest. The perseverance occasionally makes them explode. Therefore, the speaker positively deems the perseverance to have a high sense of importance and sincerity.

\subsection{Shocking}

(60) It (African honey-badger) makes shocking stinks to drive away our guards.

The Attitudinal Epithet shocking shows the speaker's personal judgment towards the Head (stinks). The speaker's personal judgment is directed to the scientific fact provided in the text following the Attitudinal Epithet. The text reveals the purpose and effect of the stinks emitted by the African honey-badger. The speaker negatively deems the stinks to be offensive or upsetting since the text elaborates the effect of the stinks, that is distracting people's concentration or attention on something.

\subsection{Silly}

(61) Silly rhymes such as: "Ladybird, ladybird. Fly away home! Your house is on fire and your children are gone!". Ladybirds don't have home. A sheltered leave is good enough for them ... No ladybird would ever fly towards a fire ... Once their eggs are laid, that's that!

The Attitudinal Epithet silly shows the speaker's personal judgment towards the Head (rhymes). The speaker's personal judgment is directed to the scientific fact provided in the text following the Attitudinal Epithet. The text reveals the reason why the speaker negatively deems the rhymes to be foolish, stupid, and ridiculous. The rhymes are foolish, stupid, and ridiculous since the content opposes the fact about the real ladybird. First of all, in the rhyme, the ladybird should fly home while in reality ladybirds dwell only on sheltered leaves. Second, once ladybirds lay their eggs, they will fly away from their eggs and will not hatch them.

\subsection{Sinister}

(62) Sinister nephila spiders spin giant webs up to 2 metres (7 feet) across to catch insects and sometimes even birds.

The Attitudinal Epithet sinister shows the speaker's personal judgment towards the subset of the Head (proper noun) nephila spiders. The speaker's personal judgment is directed to the scientific fact provided in the text following the Attitudinal Epithet. The text reveals Nephila's strategy the speaker negatively deems to be seeming evil or alarming danger. Nephila spiders are seeming evil or alarming danger since they spin giant webs, which are able to trap small animals like insects and even larger ones like birds. So the giant web must be dangerous for other animals to pass.

\subsection{Strange}

(63) Instruments trailing from the research ships far into the depths below revealed strange rises in sea temperature. Cameras lowered into the deep sea darkness had taken pictures of strange ships.

The Attitudinal Epithet strange shows the speaker's personal judgment towards the subset of the Head (rises and ships). There is no scientific fact in the text preceding or following the Attitudinal Epithet for the speaker to direct his personal judgment to. The rises in sea temperature are deemed strange based on contextual common sense based on the literal meaning of strange. The temperature is described to rise unusually or surprisingly. The ships are also deemed strange based on contextual common sense; they look unusual or surprising. The speaker's judgment over the two strange phenomena seems to be positive. They are seen to be awesome.

(64) And some of them have some horribly strange habits. Glaucus is a sea slug that floats upside down buoyed up by an air bubble inside its stomach.

The Attitudinal Epithet strange is intensified by the adverbial group horribly. It shows the speaker's personal judgment towards the Head (habits). The habits discussed are those of glaucus'. The speaker directs his personal judgment to the scientific fact revealed in the text following the Attitudinal Epithet. The text contains unusual fact that glaucus can float upside down and the fact that it can float by means of the upward pressure of air bubble inside its stomach. The speaker's judgment over the fact seems to be an awe. So, the speaker positively deems glaucus' habits difficult to understand, unusual, and surprising in a shocking way.

(65) But Greek writer, Philostratus, had some rather strange idea about spiders. He reckoned that spiders spun silk to keep warm.

The Attitudinal Epithet strange is intensified by the adverbial group rather. Lexically rather strange may be interpreted 'strange to some extent'. It shows the speaker's personal judgment towards the subset of the Head 
(idea about spider). The speaker directs his personal judgment to the scientific fact revealed in the text following the Attitudinal Epithet. In the text, Philostratus thought that spiders spun silk for the purpose of warming themselves up, different from the more logical purpose the speaker has in his knowledge. Therefore, the speaker negatively deems Philostratus' idea about spiders difficult to understand, unusual, and surprising to some extent.

(66) Can you predict the result of this strange spider experiment? ... so he fed some spiders with caffeine (that's the chemical in coffee that wakes people up) and others with sleeping pills to see what would happen.

The Attitudinal Epithet strange shows the speaker's personal judgment towards the subset of the Head (spider experiment). The speaker directs his personal judgment to the scientific fact revealed in the text following the Attitudinal Epithet. The text reveals an experiment (strategy) implemented differently to two groups of spiders; one fed with caffeine while the other with sleeping pills to see the effect from the two chemicals. Therefore, the speaker negatively deems that spider experiment to be difficult to understand, unusual, and surprising.

\subsection{Tempting}

(67) First look for some tempting aphids. They can be wide, brown, or black "greenfly" which you'll find on your rose bushes and other plants in summer.

The Attitudinal Epithet tempting shows the speaker's personal judgment towards the Head (aphids). The speaker directs his personal judgment to the scientific fact revealed in the text following the Attitudinal Epithet. The text reveals the varieties of aphids' appearance, the possible plants where they can be found, and the season when they can be easily found. Therefore, the speaker positively deems the aphids' varieties and possibly where and when they can be easily found to be attractive and alluring to people.

\subsection{Terrible}

\section{(68) Because most insect eggs are abandoned by their mothers. It's terrible, but true!}

The Attitudinal Epithet terrible functions as the Head. It shows the speaker's personal judgment towards the scientific fact revealed in the text preceding the Attitudinal Epithet. The text reveals the fact that most mother insects abandon their eggs. Therefore, the speaker negatively deems the abandonment (habit) to be very unpleasant, upsetting, and frightening as it causes great harm to the neglected eggs. The rising intonation contour (!) at the end of the clause intensifies this judgment.

\subsection{Terrifying}

(69) The bird-eating spider - a terrifying tarantula ... eats birds and frogs ... It has a painful bite ... Those hairs can give you a nasty rash.

The Attitudinal Epithet terrifying shows the speaker's personal judgment towards the Head (tarantula). The speaker directs his personal judgment to the scientific facts revealed in the texts following the Attitudinal Epithet. The first text reveals its taste over certain animals. The second reveals the painful effect of its bites. The third reveals the bad rash effect its hairs can cause to human skin. Therefore, the speaker negatively deems the tarantula to be extremely frightening.

3.46 Ugly

(70) The Australian bulldog ant has an awfully ugly bite. Not only is the bite painful but this appalling ant then squirts acid into the wound! Thirty bites can kill a human in 15 minutes.

The Attitudinal Epithet ugly is intensified by the adverbial group awfully. The intensification affirms to the listener that awfully ugly is an Attitudinal Epithet. The epithet shows the speaker's personal judgment towards the Head (bite). The bite under discussion is that of the Australian bulldog ant. The speaker directs his personal judgment to the scientific fact revealed in the text following the Attitudinal Epithet. The text reveals the painful even lethal effect of the acid the ant squirts through its bite. Therefore, the speaker negatively deems the Australian bulldog ant's bite to be terribly dangerous, threatening, and violent. The rising intonation contour (!) at the end of the clause intensifies this judgment.

(71) In fact, film designers often study ugly bugs to get good ideas for a really ugly monster.

The Attitudinal Epithet ugly is intensified by the adverbial group really. The intensification affirms to the listener that really ugly is an Attitudinal Epithet. The epithet shows the speaker's personal judgment towards the Head (monster). The speaker directs his personal judgment to the scientific fact revealed in the text preceding the Attitudinal Epithet. The text reveals the purpose film designers have by studying ugly bugs. The Nominal Group ugly bugs has the attitudinal epithet ugly to compare to the monster's appearance as the purpose of the study. 
Therefore, the speaker negatively deems the movie monster to be terribly dangerous, threatening, and violent.

(72) Ugly scenes have been reported when butterflies get drunk. It's true - the juices from rotting fruit are slightly alcoholic and even one slurp's too much for a butterfly. It flops and droops around the ground.

The Attitudinal Epithet ugly shows the speaker's personal judgment towards the Head (scenes). The speaker directs his personal judgment to the scientific fact about the scenes revealed in the text following the Attitudinal Epithet. The text reveals what happens to butterflies when they get drunk. The text reveals the effect of alcohol from rotting fruit that butterflies consume and how drunken butterflies behave. Therefore, the speaker negatively deems the 'drunken butterflies' scenes to be unpleasant to look at or unattractive.

(73) Brown-tail moth caterpillars are also pretty ugly. Their bodies are covered in sharp needle-like hairs that break off in your skin and make it itch like mad.

The Attitudinal Epithet ugly is intensified by the adverbial group pretty. The intensification affirms to the listener that pretty ugly is an Attitudinal Epithet. The Attitudinal Epithet pretty ugly functions as Head. The epithet shows the speaker's personal judgment towards Brown-tail moth caterpillars. The speaker directs his personal judgment to the scientific facts revealed in the text following the Attitudinal Epithet. The text reveals the menacing look of hairs covering Brown-tail moth caterpillar's body and the severe itch they cause to people's skin. The speaker may refer to both facts. He negatively deems the appearance and the effect to be noticeably dangerous, threatening, and violent.

\subsection{Unbelievable}

(74) But which of these beetles are too unbelievable to be true? The biscuit beetle eats, would you believe, biscuits. The cigarette beetle eats cigarettes. The violin beetle lives amongst layers of fungus in trees in Indonesia.

The Attitudinal Epithet (Head) unbelievable is intensified by the adverbial group too. The intensification affirms to the listener that too unbelievable is an Attitudinal Epithet. The Attitudinal Epithet functions as Head. The epithet shows the speaker's personal judgment towards some of the beetles mentioned afterwards. The speaker directs his personal judgment to the scientific fact revealed in the text following the Attitudinal Epithet. The text reveals three beetle species with different extraordinary kinds of food (biscuits and cigarettes) and habitats (amongst layers of fungus in trees in Indonesia). The speaker personally deems some of those beetles to be too incredible, too unrealistic, and too extraordinary to believe. The comment is an awe to the phenomena.

\subsection{Un-Boring}

(75) In fact, country people call woodlice some extremely un-boring names: bibblebugs, chookies, coffin cutters, cudworms, gammer-sows.

The Attitudinal Epithet un-boring is intensified by the adverbial group extremely. The intensification affirms to the listener that extremely un-boring is an Attitudinal Epithet. The epithet shows the speaker's personal judgment towards the Head (names). The speaker directs his personal judgment to the scientific fact revealed in the text following the Attitudinal Epithet. The text reveals interesting and unique names country people give to woodlice. Therefore, the speaker positively deems the names country people give to woodlice to be very interesting, exciting, and inspiring.

\subsection{Unfortunate}

(76) When they (traditional butterfly hunters) caught an unfortunate flutterer they plunged it into a bottle of poison and pinned it to a board.

The Attitudinal Epithet unfortunate shows the speaker's personal judgment towards the Head (flutterer). The flutterer under discussion is how the speaker calls butterflies. The speaker directs his personal judgment to the fact revealed in the text following the Attitudinal Epithet. The text reveals the way traditional butterfly hunters catch and preserve butterflies. Since the process involves poison and board pins, the speaker negatively deems the flutterer or butterfly to be unlucky or ill-fated when caught by those hunters. The fate is the effect of the hunt.

\subsection{Useful}

(77) And amazingly enough some ugly bugs are even horribly useful to humans. We rely on ugly bugs to make plants fruit and to eat up rotten plant rubbish.

The Attitudinal Epithet useful is intensified by the adverbial group horribly. The intensification affirms to the listener that horribly useful is an Attitudinal Epithet. The epithet functions as Head. It shows the speaker's 
personal judgment towards some ugly bugs. The speaker directs his personal judgment to the scientific fact revealed in the text following the Attitudinal Epithet. The text reveals the values or functions the bugs serve to humans, to help plants bear fruit and to help clean the environment by eating rotten plant rubbish. Therefore, the speaker positively deems some ugly bugs to be helpful, valuable, and serving purposes to humans.

\subsection{Weird}

(78) Every summer a primary school in Nantwich, England host a weird competition. It's the world worm charming championship. What a charming traditional pastime!

The Attitudinal Epithet weird shows the speaker's personal judgment towards the Head (competition). The competition under discussion is the one held every summer by a primary school in Nantwich, England. The speaker directs his personal judgment to the cultural fact revealed in the text following the Attitudinal Epithet. The text reveals the purpose of the competition, which is to compete in charming a worm. Since such competitions do not indicate harm, the speaker must deem the idea of the competition to be very strange, unusual, and difficult to explain in a positive sense.

(79) But one thing they all have in common is that they are horribly weird. ... Why did they look so weird? The strange red tips of the creatures waved in the sea.

The Attitudinal Epithet weird is intensified by the adverbial group horribly. The intensification affirms to the listener that horribly weird is an Attitudinal Epithet. The lexical meaning of horribly is in an unpleasant, frightening, distressing, and shocking way. The epithet functions as Head. It shows the speaker's personal judgment towards the creatures. The speaker directs his personal judgment to the scientific fact revealed in the text following the Attitudinal Epithet. Another Attitudinal Epithet strange as the synonym of weird is present in the text to modify the Head red tips. This provides further emphasis to the horribly weird appearance as part of and mark the presence of the sea creatures. Therefore, the speaker negatively deems the creatures to be very strange, unusual, and eerie.

\subsection{Wrong}

(80) Centipede means "hundred feet". But once again the scientists got it horribly wrong! Many centipedes have fewer than 30 feet.

The Attitudinal Epithet wrong is intensified by the adverbial group horribly. The intensification affirms to the listener that horribly wrong is an Attitudinal Epithet. The rising intonation contour (!) marking the end of the clause also affirms horribly wrong to be an Attitudinal Epithet. The lexical meaning of horribly is in an unpleasant, frightening, distressing, and shocking way. The epithet functions as Head and shows the speaker's personal judgment towards the lexical definition of centipedes. The speaker directs his personal judgment to the scientific fact revealed in the text preceding and following the Attitudinal Epithet. The text reveals the true number of feet of many centipedes. Centipedes' turn out to have much fewer than 'hundred' feet, while the lexical meaning of prefix 'centi-' is 'hundred'. Therefore, the speaker negatively deems the common definition to be incorrect, mistaken, or not right.

\section{Discussion}

There are fifty-two lexical variants of Attitudinal Epithets occuring in the data, broken down into eighty with distinct features. Most attitudinal Epithets (62\%) are considered to have negative polarity, such as awful, bad, boring, complicated, confusing, cruel, loathsome, nasty, revolting, shocking, silly, sinister, terrifying, unfortunate, and untidy. $32 \%$ are considered to have positive sense, such as amazing, awesome, brilliant, cunning, cute, dramatic, funny, incredible, lovely, precious and tempting. $6 \%$ are bipolar epithets, which may have both positive or negative sense, depending on the fact referred by the epithet. They are interesting, strange, and weird.

The system of Attitudinal Epithet intensification occurs in the data and intensifies the personal or subjective sense of the speaker's comments. Some of them are intensified by adverbial groups, and they are awesomely, awfully, deadly, extremely, more, most, horribly, pretty, quite, rather, really, seriously, so, terrifically, too, and very. Some are intensified by a synonymous epithet, and they are big strong, cruel cunning, dull and boring, horrible gruesome, odd interesting, and poor little. Ten Attitudinal Epithets are intensified by the rising intonation contour. An exclamation, Yuk! and a tag doesn't it also occur. In terms of some bipolar indication in the paragraph above, there are distinctions in relation to this system of intensification. When the epithet interesting is not intensified, it tends to be positive. Meanwhile horribly interesting and odd interesting tend to be negative as the literal meaning of horrible and odd has negative sense. The intensifier horribly intensifies strange, horribly strange, indicating a negative sense. While with two un-intensified epithets strange, one is a negative and the other is a positive comment, an awe to a fact. The epithet horribly weird is used to give a 
negative comment, while un-intensified weird to give a positive comment, an awe to a fact. Despite the common tendency of negativity of horrible, there is one occurrence of intensifier horribly which is used to intensify a positive comment - horribly useful.

As the children's book provides scientific information, the Attitudinal Epithets are directed to scientific, cultural, or other facts provided in the text preceding or following the epithet. Most Attitudinal Epithets (65\%) are directed to scientific, cultural, or other facts provided in the text following the epithets. The second highest number of Attitudinal Epithets (15\%) is directed to scientific, cultural, or other facts provided in the text preceding the epithets. The third highest number of Attitudinal Epithets (14\%) is directed to scientific, cultural, or other facts provided in the text preceding and following the epithets. The least portion $(6 \%)$ is directed to contextual common sense.

\section{References}

Arnold, N. (2007). Ugly Buggs. London: Scholastics Ltd.

Beller, C. (n.d.). Accent and Description: An Account of Anaphoric Epithets. John Hopkins University. Retrieved March 28 ,

2013 , http://www.researchgate.net/publication/43648019_Accent_and_description_An_account_of_anaphoric_epi thets

Bloor, T., \& Bloor, M. (2004). The Functional Analysis of English: A Hallidayan Approach (2nd ed.). London: Hodder Education.

Bungin, H. M. B. (2007). Penelitian Kualitatif Komunikas, Ekonomi, Kebijakan Publik, dan Ilmu Sosial Lainnya. Jakarta: Fajar Interpratama Offset.

Djajasudarma, T. F. (1993). Metode Linguistik. Bandung: PT. Eresco.

Eggins, S. (2004). An Introduction to Systemic Functional Linguistics (2nd ed.). New York - London: Continuum.

Encarta Dictionary. (2008). 1993-2007 Microsoft Corporation.

Gerot, L., \& Wignell, P. (1995). Making Sense of Functional Grammar (2nd ed.). Sidney: Antipodean Educational Enterprises.

Halliday, M. A. K. (1994). Functional Grammar (2nd ed.). London: Edward Arnold, a member of the Hodder Headline Group.

Halliday, M. A. K., \& Martin, J. R. (1993). Writing Science: Literacy and Discursive Power. London \& Washington, D.C.: The Falmer Press.

Halliday, M. A. K., \& Matthiessen, C. (2004). An Introduction to Functional Grammar (3rd ed.). New York: Oxford University Press. Inc.

Hornby, A. S. (2005). Oxford Advanced Learner's Dictionary of Current English (7th ed.). New York: Oxford University Press.

Lemke, J. L. (1990). Talking Science: Language, Learning and Values. Norwood, New Jersey: Ablex.

Lemke, J. L. (in review). Resources for Attitudinal Meaning: Evaluative Orientations in Text Semantics. Functions of Language. Retrieved March 28, 2013, from $\mathrm{http} / / /$ academic.brooklyn.cuny.edu/education/jlemke/editorl.htm

Martin, J. R., \& Rose, D. (2008). Genre Relations: Mapping Culture. London: Equinox Publishing Ltd.

Muhammad, M. H. (2011). Metode Penelitian Bahasa. Jogjakarta: AR-RUZZ Media.

Thompson, G. (2004). Introducing Functional Grammar (2nd ed.). London: Arnold - Hodder Headline Group.

\section{Copyrights}

Copyright for this article is retained by the author(s), with first publication rights granted to the journal.

This is an open-access article distributed under the terms and conditions of the Creative Commons Attribution license (http://creativecommons.org/licenses/by/3.0/). 